\title{
Importância da velocidade do movimento celular na câmara anterior, na avaliação clínica das uveítes
}

\author{
Importance of the speed of the cellular movement in the anterior chamber in the \\ clinical evaluation of uveitis
}

Fernando Antônio L. Mendes Furtado ${ }^{(1)}$ Edmar Oliveira Guedes Júnior ${ }^{(2)}$ Déborah Bandeira Fernandes Távora ${ }^{(2)}$

\section{RESUMO}

Objetivo: Acrescentar ao oftalmologista mais um dado para avaliação clínica das uveítes, que acometem o segmento anterior; seja contribuindo para revelar a intensidade do processo inflamatório, seja ajudando a nortear a conduta terapêutica.

Métodos: Estudamos 46 pacientes portadores de uveíte e com reação celular na câmara anterior. Observamos a velocidade do deslocamento das células no humor aquoso e a relacionamos com a intensidade do processo inflamatório, comparando com a sintomatologia e principais sinais clínicos.

Resultados: Os resultados nos mostram que existe uma correlação direta entre a velocidade das células na câmara anterior e o grau de inflamação. Quanto mais grave a inflamação, menor é o deslocamento das células. $E$ podemos aplicar esse fato na abordagem clínica das uveítes. Em algumas situações é mais fácil perceber alterações na velocidade que na quantidade de células ou flare.

Conclusões: Nosso estudo apresenta um elemento novo na semiologia das uveítes, já que não encontramos referências na literatura médica. Familiarizando-se com a velocidade dos movimentos celulares na câmara anterior, podemos dispor de uma valioso recurso que nos ajude no exame do paciente com uveíte. Há casos em que a mudança na velocidade é oúnico elemento a nos indicar uma piora ou melhora do quadro clínico.

Palavras-chave: Uveítes; Diagnóstico das uveítes; Células na câmera anterior; Propedêutica das uveítes; Movimento celular.

\section{INTRODUÇÃ̃O}

Para o diagnóstico e acompanhamento das uveítes, o exame clínico é fundamental. Alguns sintomas, e principalmente uns poucos sinais clínicos tais como hiperemia pericerática, hipópio, flare, células e opacidades vítreas orientam o oftalmologista. Nas uveítes anteriores ou com repercussão no segmento anterior, na grande maioria das vezes, a presença de flare e células na câmara anterior são os elementos principais para o diagnóstico e evolução da inflamação ${ }^{1,2}$. Graduações de células e flare são usadas, porém sabemos que existe grande variações entre os autores ${ }^{3,4}$. Além disso, na prática, nem sempre é fácil a classificação do flare e a contagem de células ${ }^{5}$. O Laserflarefotômetro, aparelho que quantifica o flare, devido ao alto custo, não foi difundido.

Devido a diferença de temperatura entre a íris e a córnea, existe uma corrente térmica no humor aquoso, com uma parte ascendente próximo a íris mologia - setembro de 1999 - Recife- PE.

Sociedade de Assistência aos Cegos, Fortaleza Ceará.

Preceptor da residência médica da Sociedade de Assistência aos Cegos.

Residentes do $2^{\circ}$ ano em oftalmologia da Sociedade de Assistência aos Cegos.

Endereço para correspondência: Dr. Fernando Furtado. R. Deputado Moreira da Rocha, 542/1100. CEP 60160-060 - Fortaleza (CE). e-mail: fernoft@fortalnet.com.br 
onde a temperatura é maior, e uma descendente próximo a córnea onde a temperatura é menor ${ }^{1,6}$ (Figura 1). Está documentado na literatura a paralisação ou coagulação que ocorre no humor aquoso, em casos graves de inflamação ${ }^{1,7}$. Contudo, não encontramos relatos citando a importância da velocidade do deslocamento das células nos vários estágios de intensidade do paciente com uveíte. Sabe-se que quando a barreira hematoaquosa é quebrada, há passagem de proteínas e células inflamatórias para a câmara anterior. Quanto mais severa é a inflamação, mais permeável se torna a barreira e maior será o extravasamento, tornando o tráfego mais congestionado na câmara anterior, e o movimento celular consequentemente mais lento.

Observamos que a velocidade do movimento celular na câmara anterior está diretamente relacionado ao grau de inflamação, e assim como o número de células e o flare, pode ser um elemento a mais na abordagem das uveítes.

O objetivo desse trabalho é acrescentar ao arsenal do oftalmologista, mais um elemento na avaliação clínica das inflamações oculares que acometem o segmento anterior. Não encontramos referências na literatura médica.

\section{MATERIAL E MÉTODOS}

Examinamos 46 pacientes portadores de uveítes, nos quais o segmento anterior estava comprometido e haviam células na câmara anterior. Procuramos correlacionar a velocidade de deslocamento das células, com o grau de inflamação, comparando com as graduações de contagem de células e de flare, e com a sintomatologia do paciente. Usamos tratamento antiinflamatório inespecífico em todos os casos e específico quando necessário. Não nos preocupamos em associar nossas observações com a etiologia da uveíte nem com o tipo de

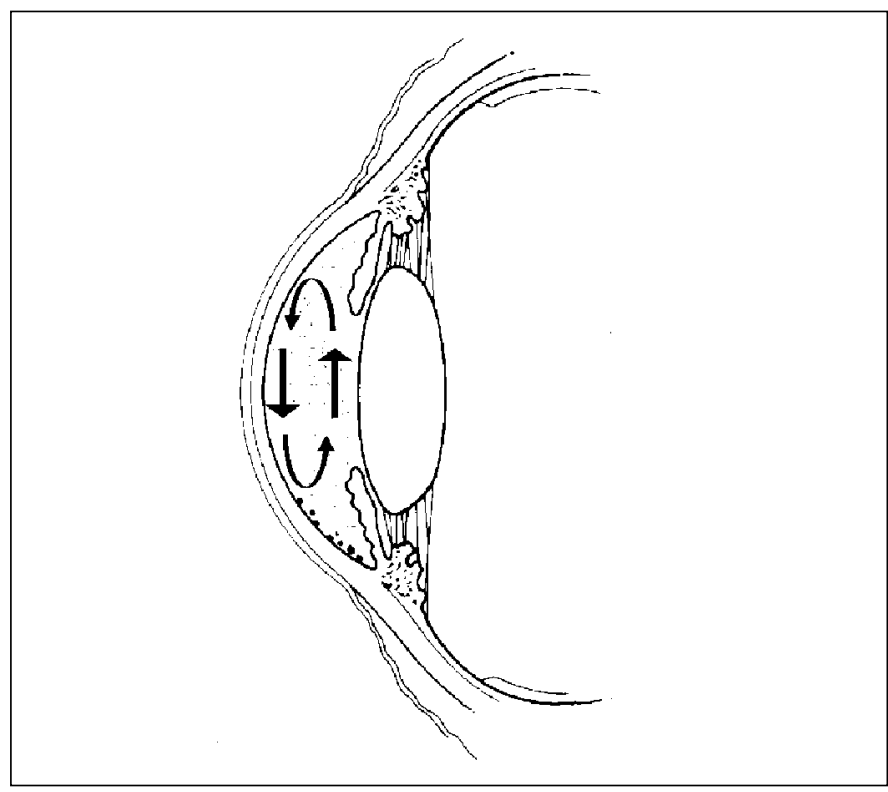

Fig. 1 - Correntes térmicas na câmera anterior. As células circulam no sentido das setas. tratamento usado, apenas comparamos a velocidade do movimento celular com os sinais e sintomas dos pacientes. Observamos os deslocamentos celulares, tanto na corrente ascendente como descendente e em pontos variados da câmara anterior, usamos fendas de 2, 1 e 0,2 milímetros. Concentramos nosso estudo, mormente na corrente ascendente, ao nível da pupila, usando um feixe de luz de um milímetro, com aumento de dezesseis vezes da lâmpada de fenda, e em ambiente escuro.

\section{RESULTADOS}

Os resultados nos levam a crer que existe uma correlação direta, entre a velocidade da massa celular e a atividade inflamatória do segmento anterior. Quanto mais grave é a uveíte, menor tende a ser o deslocamento das células. A velocidade das células ao nível da pupila na corrente ascendente varia desde um milímetro por 4 a 7 segundos, em média, nos casos leves, até a parada total das partículas, nos casos mais graves.

Nos nossos casos houve uma correspondência tanto do nível de flare, quanto da contagem de partículas na câmara anterior, quanto da sintomatologia, com a variação da velocidade celular.

Quando a velocidade celular aumenta ou diminui é porque a inflamação está melhorando ou piorando, respectivamente. Temos assim uma idéia da evolução da uveíte. As mudanças na velocidade celular ocorrem principalmente com contagem de células entre $+2 \mathrm{a}+4$. Com contagem de células de zero a +2 o movimento celular geralmente costuma ser praticamente normal, segundo nossa classificação.

Para efeito de classificação, chamamos a velocidade dos casos leves de normal. Quando o movimento está normal ou próximo do normal, indica que há poucos elementos inflamatórios na câmara anterior. Por outro lado, se esse movimento é lento ou muito lento, estamos diante de uma inflamação mais grave. Em ambos os casos, a observação da velocidade celular nos dá uma idéia da gravidade da uveíte (Tabela 1).

\section{DISCUSSÃO}

Em doenças graves como as uveítes, onde muitas vezes os exames laboratoriais e complementares pouco auxiliam, os sinais clínicos são nossos únicos aliados para avaliarmos e evoluirmos nossos pacientes. Portanto um sinal a mais nessa avaliação, no caso, a velocidade do movimento celular na câmara anterior, torna-se valioso.

As células se constituem principalmente de linfócitos e neutrófilos, podendo haver hemácias e pigmentos, dependendo do caso $^{3,7}$. A presença de células na câmara anterior é o sinal principal da presença da atividade inflamatória, embora nem sempre indique inflamação ${ }^{7}$. Não apenas a quantidade de células, mas também o tamanho das células é importante, sendo maior quanto mais intensa for a uveíte ${ }^{5}$. Nosso trabalho procura ressaltar a velocidade com que as células se deslocam no humor aquoso. 


\begin{tabular}{|ll|}
\hline $\begin{array}{l}\text { Tabela 1. Graduação da velocidade das células na câmara anterior } \\
0\end{array}$ & $\begin{array}{l}\text { Velocidade normal - estados iniciais, casos leves, } \\
\text { pós-operatório de catarata não complicada }\end{array}$ \\
$1+$ & Velocidade um pouco lenta \\
$2+$ & Velocidade lenta \\
$3+$ & Velocidade muito lenta \\
$4+$ & Parada celular - Coagulação do humor aquoso \\
Observação: Velocidade celular da corrente ascendente no meio da pupila. \\
Usando fenda luminosa de 1x1mm. Aumento de 16x.
\end{tabular}

Notadamente nos casos de quantidade de células com três e quatro cruzes, a percepção do aumento ou diminuição do número de células é muito difícil, as vezes, impossível. Nestes casos a intensidade do flare, geralmente, parece não variar. Melhoras ou pioras do quadro clínico, discretas a moderadas, foram mais fáceis de perceber, observando-se a mudança da velocidade celular, do que as alterações na quantidade de células e flare. Esta observação pode ser de grande valia na orientação terapêutica, mormente na evolução da uveíte, auxiliando na decisão de manter ou alterar a medicação.

Tivemos alguns casos em que os pacientes referiram melhora da visão e sintomatologia ocular, e não notamos diferença no flare ou número de células, nem hiperemia. $\mathrm{O}$ único sinal que corroborava com a afirmativa do paciente, foi um aumento na velocidade das partículas, que dois dias antes estavam mais lentas. Na evolução do quadro, os pacientes tiveram melhora progressiva. Assim, o aumento da velocidade celular foi o único parâmetro objetivo, a nos indicar uma melhora do quadro.

Duke Elder relata como normal a velocidade de 1 milímetro por 3 a 4 segundos, na corrente ascendente, que é a parte mais rápida das correntes térmicas ${ }^{6}$. Encontramos nos casos leves, a velocidade igual a 1 milímetro por 4 a 7 segundos. $\mathrm{O}$ mesmo pode ser observado, nas fases iniciais da inflamação e quando esta entra na fase final de resolução. Pode-se achar essa velocidade, normalmente após traumas cirúrgicos, como na cirurgia de catarata, onde há quebra da barreira hematoaquosa (Esses casos seriam o 0-Normal, na nossa classificação (Tabela 1).

Tentamos fazer uma graduação baseada nas velocidades encontradas, o que seria ideal, porém existem algumas dificuldades, tais como: pestanejar, pequenos movimentos involuntários e tamanho da fenda. Tentamos medir usando a fenda de 1 milímetro e 0,2 existentes na lâmpada de fenda, contudo acreditamos que se houvesse uma fenda de 0,5 ou 0,6 , poderíamos conseguir. Isso é motivo para estudos posteriores.

Depois que inicia-se a observação da velocidade celular, logo adquire-se experiência e começa-se a graduar normalmente. Lembrando sempre, que os pacientes com uveíte são vistos a intervalos pequenos de tempo, o que facilita as evoluções, através de comparações da velocidade do mesmo paciente, no período de um a poucos dias. Ao contrário do que se possa pensar, não é difícil ver mudanças nos deslocamentos celulares. Aprende-se rápido, mormente familiarizando-se com os casos de velocidade normal, além de que, nos casos onde a inflamação é mais intensa, com celularidade aumentada, as células costumam ser maiores e mais numerosas ${ }^{5}$, o que facilita a visualização do deslocamento.

Vale ressaltar, que devemos observar células que pertencem a massa celular como um todo, evitando pigmentos ou partículas solitárias, que muitas vezes possuem velocidades diferentes.

\section{SUMMARY}

Purpose: To add for the ophthalmologist an element for clinical evaluation of uveitis, affecting the anterior segment; contributing both to reveal the intensity of the inflammatory process and helping to guide the therapeutic management conduct.

Methods: We studied 46 uveitis patients with cellular reaction in the anterior chamber. We observed the speed of the displacement of the cells in the aqueous humor and related it to the intensity of the inflammatory process, in comparison with the symptomatology and main clinical signs.

Results: The results showed that there is an inverse correlation between the speed of cells in the anterior chamber and the degree of inflammation. The more serious was the inflammation, the less was the displacement of the cells. And we can apply this fact to the clinical evaluation of uveitis. In some situations it was easier to notice alterations in the speed of the cells than in the amount of cells or flare. Conclusions: Our study presents a new element in the semiology of uveitis, since we did not find references in the medical literature. On familiarizing with the speed of the cell movements in the anterior chamber, we may have a valuable resource that helps us in the patient's examination of uveitis. In some cases the change in the speed is the only element indicating a worsening or improvement in the clinical course.

Keywords: Uveitis; Diagnosis of uveitis; Cells in anterior chamber; Examination of uveitis; Cellular movement.

\section{REFERÊNCIAS BIBLIOGRÁFICAS}

1. Hogan MJ, Kimura SJ Thygeson P. Signs and symptoms of uveitis. I. Anterior uveitis. Am J Ophthalmol 1959;47:155-70.

2. Opremcak EM. Uveitis-A Clinical Manual for Ocular Inflammation, $1^{\text {a }}$ Edition, New York. Springer-Verlag, 1995. Chapter 2.

3. Oréfice F, Belfort Jr R. Uveítes - (Conselho Brasileiro de Oftalmologia ), $1^{\mathrm{a}}$ Edição, São Paulo, Livraria Roca Ltda, 1987. Capítulo 7.

4. Oréfice F, Menin BL. Caderno de Uveítes, $1^{\text {a }}$ Edição, Belo Horizonte, Alcon Laboratórios do Brasil Ltda, 1994. Capítulo 2.

5. Nussenblatt RB, Whitcup SM, Palestine AG. Uveitis-Fundamentals and Clinical Practice, 2a Edition, St. Louis. Mosby, 1996. Chapter 4.

6. Duke-Elder S Gloster J. The Physiology of the Eye and of Vision: System of Ophthalmology. London, Kimpton, 1968. Chapter 2.

7. Tessler HH. Classification and Symptoms and Signs of Uveitis. In: Tasman W, Jaeger EA, eds. Duane's Clinical Ophthalmology. Philadelphia: JB Lippincott, 1998; v.4, chapter 32. 